\title{
DUAS FACES DO MESMO CLIL: A \\ INTEGRAÇÃO DE CONTEÚDO E LÍNGUA NA \\ FORMAÇÃO DE PROFESSORES E EM PROJETOS \\ PARA O ENSINO DE ITALIANO EM ESCOLAS \\ PÚBLICAS BRASILEIRAS
}

\section{Due facce dello stesso CLIL: l'integrazione di contenuto e lingua nella formazione degli insegnanti e nei progetti per l'insegnamento dell'italiano nelle scuole pubbliche brasiliane}

\author{
Two Sides of the Same CLIL: Content and Language \\ Integration in Teacher Education and in Projects \\ Aimed at Teaching Italian in Brazilian Public Schools
}

Adriana Mendes Porcellato*

RESUMO: Este estudo foi conduzido no contexto de um programa multicultural para capacitar professores de diferentes disciplinas na rede pública municipal de São Paulo a ofertar projetos de língua italiana aos alunos de suas escolas. Os dados apresentados neste artigo foram coletados durante a preparação didática, em que a abordagem CLIL (Content and Language Integrated Learning), que promove a aprendizagem integrada de língua e conteúdo (cf. COYLE, HOOD e MARSCH, 2010), teve dúplice função: por um lado, as aulas do curso de formação foram elaboradas seguindo essa abordagem; por outro, o CLIL foi um dos conteúdos tratados no curso e influenciou os projetos finais elaborados pelos professores. Analisando as atividades didáticas utilizadas no curso, o diário da formadora, os projetos finais e os questionários respondidos pelos professores, percebeu-se que a implementação da modalidade CLIL exige diversos conhecimentos por parte do docente e, em especial, uma sensibilidade linguística (HE e LIN, 2018) específica que permita identificar pontos de integração entre o conteúdo

*Docente - Universidade Federal da Bahia

adriana.porcellato@outlook.com (ORCID: 0000-0001-6644-6038)

DOI: http://dx.doi.org/10.11606/issn.2238-8281.v0i42p64-91 
ensinado e os aspectos linguísticos necessários para a aquisição. As análises mostraram que, durante a preparação didática e com o apoio da formadora, os professores começaram a adquirir, mesmo que só parcialmente, essa sensibilidade. Apesar de apresentar desafios, a abordagem CLIL pode ser um caminho promissor quando aplicada ao contexto de formação de professores e ao ensino da língua italiana.

PALAVRAS-CHAVE: CLIL; Formação de professores; Italiano L2; Escola pública.

ABSTRACT: Questo studio è stato realizzato nel contesto di un programma multiculturale per abilitare gli insegnanti di diverse discipline della scuola pubblica della città di San Paolo a offrire progetti per l'insegnamento della lingua italiana. I dati presentati in questo articolo sono stati raccolti durante la preparazione didattica, in cui l'approccio CLIL (Content and Language Integrated Learning), che promuove l'apprendimento integrato di contenuto e lingua (cfr. COYLE, HOOD e MARSCH, 2010), ha avuto una duplice funzione: da una parte, le lezioni del corso di formazione sono state elaborate seguendo questo approccio; dall'altra, il CLIL costituiva uno dei contenuti trattati nel corso e ha influenzato i progetti finali elaborati dagli insegnanti. Analizzando le attività didattiche utilizzate nel corso, il diario della formatrice, i progetti finali e i questionari compilati dagli insegnanti, si è notato che l'implementazione della modalità CLIL esige diverse conoscenze da parte del docente e, in particolare, una sensibilità linguistica (HE e LIN, 2018) specifica che permetta di identificare punti di integrazione tra il contenuto insegnato e gli aspetti linguistici necessari per l'acquisizione. Le analisi hanno dimostrato che, durante la preparazione didattica e con il sostegno della formatrice, gli insegnanti hanno cominciato ad acquisire, anche se solo parzialmente, questa sensibilità. Nonostante presenti difficoltà, l'approccio CLIL può essere un approccio promettente applicato al contesto di formazione di insegnanti e all'insegnamento della lingua italiana.

PAROLE CHIAVE: CLIL; Formazione di insegnanti; Italiano L2; Scuola pubblica.

ABSTRACT: This study was carried out inside the context of a multicultural program aimed at enabling teachers of different subject matters of public schools to offer projects of Italian to their students. The data presented in this paper were collected throughout the pedagogical preparation, during which CLIL (Content and Language Integrated Learning), which promotes the integration of content and language (cf. COYLE, HOOD e MARSCH, 2010), served a double function: on the one hand, the classes of the teacher development course were designed following this approach; on the other hand, CLIL was one of the contents dealt with in the course and ended up informing the teachers' final projects. Analyzing the pedagogical activities used in the course, the teacher educator's diary, the final projects and the questionnaire filled in by the teachers, it was noticed that implementing CLIL requires a range of "knowledges" on the part of the teacher and, above all, a specific teacher language awareness (HE e 
LIN, 2018) that enables teachers to identify how language and a certain content integrate. The analyses showed that, during the pedagogical preparation and with the help of the educator, teachers acquired this awareness, even if only partially. In spite of its challenges, CLIL may be a promising path in the contexts of teacher education and of Italian language teaching.

KEYWORDS: CLIL; Teacher education; Italian L2; Public school. 


\section{Introdução}

Este trabalho foi desenvolvido dentro do contexto de uma recente iniciativa da Secretaria Municipal de Educação (doravante SME) da cidade de São Paulo em parceria com o consulado italiano e com a colaboração do Instituto Cultural Ítalo-Brasileiro (doravante ICIB) e do Programa de Pós-Graduação em Língua, Literatura e Cultura Italianas da Universidade de São Paulo (USP). Em 2018, esses órgãos se uniram para implementar um Programa de Formação Multicultural em Língua Italiana (PFMLI), com aulas de língua e de didática, no intuito de capacitar professores de diferentes disciplinas a ofertar projetos de língua italiana aos alunos da rede municipal. Esse programa é particularmente relevante para a cidade de São Paulo, onde, apesar de a influência da imigração italiana ser fortemente presente (cf. CAPRARA e MORDENTE, 2004), o acesso à língua italiana no ensino público é ainda consideravelmente limitado, podendo contar somente com os CELs (Centro de Estudos de Línguas) das escolas estaduais e com poucos projetos de curta duração oferecidos no contraturno por iniciativa de professores das escolas municipais (ORTALE e ZORZAN, 2013). O projeto é também importante no contexto do ensino de línguas no território nacional, especialmente se considerarmos que "a maioria da população no Brasil só tem acesso ao ensino e à aprendizagem de uma língua estrangeira se esta for ofertada de maneira pública e gratuita” (CARAMORI, 2018, p. 10). Sabemos, porém, que na maioria das escolas públicas os alunos têm acesso a línguas hegemônicas, como inglês e espanhol, não havendo espaço para outros idiomas. Assim, em São Paulo, o italiano continua sendo uma língua de difícil acesso, apesar de desempenhar um papel relevante por fatores culturais, afetivos, identitários e econômicos (ORTALE e ZORZAN, 2013; SERRAGIOTTO, 2014). Além das questões afetivas e identitárias, que talvez interessem principalmente aos descendentes de italianos, precisamos também considerar que, em um mundo sempre mais globalizado, o plurilinguismo adquire importância cada vez maior e, portanto, a habilidade de comunicar em mais de uma língua acaba se tornando uma competência importante, que deve ser promovida na escola (SERRAGIOTTO, 2012; PÉREZ CAÑADO, 2017).

Neste artigo, nos concentraremos em um grupo de professores de diferentes disciplinas na Rede Municipal de Ensino de São Paulo (doravante RMESP) que, após completarem o percurso linguístico inicial, realizaram a fase do PFMLI dedicada ao chamado "suporte didático" (SD). Nessa etapa, as aulas, conduzidas em italiano, foram elaboradas de forma a introduzir conceitos básicos relacionados ao ensino de línguas adicionais e, ao mesmo tempo, a promover as habilidades linguísticas dos professores. Pelo fato de as aulas serem dedicadas tanto à aprendizagem de conteúdos de didática quanto ao estudo da língua, pode-se dizer que foram ministradas com base na abordagem CLIL (Content and Language Integrated Learning), em que se promove a aprendizagem integrada de língua e conteúdo (cf. COYLE, HOOD e MARSCH, 2010; SERRAGIOTTO, 2012). Nesse contexto, o CLIL teve duplo papel: ao mesmo tempo em que constituiu a abordagem em que foram elaboradas as aulas do suporte didático, foi também um dos conteúdos tratados durante as aulas, influenciando os projetos elaborados pelos professores-aprendizes durante o semestre. 
Nosso objetivo neste trabalho é, portanto, refletir sobre a dúplice função da abordagem CLIL no contexto específico de formação de professores aqui analisado, concentrando-nos nas potencialidades e nos obstáculos observados tanto nas aulas ministradas pela formadora, quanto na elaboração de projetos para a promoção da língua italiana entre os alunos da escola pública.

As próximas seções foram organizadas da seguinte forma: primeiramente, será apresentada uma definição da abordagem CLIL, identificando seus princípios teóricos e metodológicos e suas tipologias; em seguida, será descrito o contexto específico em que os dados foram coletados e analisados, para depois passar às análises do dúplice papel da abordagem CLIL nesse contexto. Por último, serão apresentadas considerações e reflexões acerca dos resultados apresentados e suas implicações para projetos futuros.

\section{Fundamentação teórica}

\subsection{O que é CLIL?}

O termo CLIL, acrônimo inglês de Content and Language Integrated Learning (que, em português, corresponderia a Aprendizagem Integrada de Conteúdo e Língua - AILC) ${ }^{1}$, foi cunhado nos anos 1990 e começou a ser usado a partir de 1994 para descrever a prática, cada vez mais difundida nas escolas europeias, de ensinar/aprender alguns conteúdos por meio de uma língua adicional, que, muitas vezes, acabava sendo o inglês (COYLE et al., 2010; SERRAGIOTTO, 2012; HEMMI e BANEGAS, 2021).

Desde então, as definições de CLIL têm sido várias: ora foi considerado como um construto para promover o ensino e a aprendizagem de línguas estrangeiras, ora como um tipo de aprendizagem de língua baseada em contexto, ora como uma metodologia inovadora e uma nova tendência no ensino de línguas (CAÑADO e PADILLA, 2015). Coyle et al. (2010) concordam que se trata, de fato, de algo inovador, que nasceu e cresceu em resposta às demandas e às expectativas da era moderna do conhecimento (knowledge age), no entanto, não consideram que o CLIL seja simplesmente uma metodologia ou que contemple somente a esfera do ensino e aprendizagem de línguas. Segundo eles, trata-se de uma abordagem educacional (educational approach) para todos os efeitos, cujo objetivo é garantir uma dupla aprendizagem: por um lado, a língua é aprendida por meio do conteúdo; por outro, o conteúdo (um assunto específico ou uma matéria) é aprendido por meio da língua. É justamente essa integração entre aprendizagem de conteúdo e de língua que diferencia o CLIL de outras abordagens, como a aprendizagem baseada em conteúdo (content-based learning), ou da própria aula de língua estrangeira (LE) ou segunda língua (L2) ${ }^{2}$. De fato, se na aula de LE o objetivo principal é o ensino e aprendizagem

1 Optamos por utilizar o acrônimo CLIL, da língua inglesa, pois o correspondente em português não parece ter a mesma difusão, até mesmo na literatura em língua portuguesa.

2 Estamos cientes de que existe uma distinção entre dois contextos de aprendizagem de línguas: o de L2 e o de LE (cf. RINGBOM, 1979). Neste trabalho, no entanto, os termos língua estrangeira (LE), segunda língua (L2), 
da língua, com o professor que assume o papel de ensinar e o aluno, o papel de aprender, no CLIL a relação com a língua é completamente diferente: o professor tem o papel de promover a L2 enquanto ensina outros conteúdos, ao passo que o aprendiz faz uso da L2 para aprender o conteúdo da matéria ensinada (Quadro 1).

Quadro 1 - Aula de língua estrangeira e CLIL

\begin{tabular}{|l|l|l|}
\hline & Lingua straniera & Lingua veicolare (CLIL) \\
\hline l'insegnante & insegna la lingua & promuove la lingua \\
\hline lo studente & impara a usare la lingua & usa la lingua \\
\hline
\end{tabular}

Fonte: Balboni, 2015, p. 213

Pode-se dizer, então, que o CLIL não é nem uma abordagem de ensino/aprendizagem de língua, nem uma abordagem de ensino/aprendizagem de outras matérias, mas uma combinação das duas, na qual o ensino/aprendizagem de língua e de conteúdo convergem (COMISSÃO EUROPEIA, 2006; COYLE et al., 2010). Por sua abrangência, considera-se que CLIL é um "termo guarda-chuva" (DALTON-PUFFER; NIKULA; SMIT, 2010) que envolve diferentes modelos e métodos e, por isso, pode ser considerado flexível por muitos aspectos. Essa flexibilidade é, em parte, responsável pela grande difusão do CLIL, especialmente a partir dos anos 2000 (COYLE et al., 2010).

\subsection{Princípios teóricos e metodológicos da abordagem CLIL}

Vimos que o modelo CLIL se caracteriza por sua flexibilidade e adaptabilidade a diferentes contextos, mas isso não significa que possa prescindir de uma base teórica sólida e de princípios norteadores firmes. As escolhas metodológico-didáticas do CLIL necessitam, por um lado, promover a aprendizagem de língua e conteúdo (COONAN, 2009) e, por outro, contemplar as características essenciais da "era do conhecimento", ou seja, a aprendizagem participativa, a pesquisa e a inovação (COYLE et al., 2010). Por isso, o CLIL é implementado na sala de aula por meio de metodologias em que os alunos são "participantes ativos no desenvolvimento de seu potencial para aquisição de conhecimento e de habilidades por meio da investigação (pesquisa) e usando processos e meios cognitivos complexos para resolver problemas (inovação)"’3 (COYLE et al., 2010, p. 5). Fazendo jus a seu caráter inovador, as metodologias didáticas do CLIL tendem a seguir a lógica do "learn as you use, use as you learn" (aprenda enquanto usa, use enquanto aprende), muito diferente da lógica do "aprender agora para usar depois" (learn

língua adicional e língua veicular serão usados como sinônimos para indicar a língua não materna. A língua materna será indicada como L1.

3 "active participants in developing their potential for acquiring knowledge and skills (education) through a process of inquiry (research) and by using complex cognitive processes and means for problem solving (innovation)" (COYLE et al., 2010, p. 5). 
now for use later). A abordagem CLIL é também reconhecida por se pautar em teorias socioculturais e construtivistas (SERRAGIOTTO, 2012; NAHARRO, 2019; HEMMI e BANEGAS, 2021), em que as aulas são planejadas com base na aprendizagem participativa e cooperativa, com o professor atuando como um mediador e facilitador que fornece aos aprendizes material autêntico compreensível. De fato, o professor de CLIL, além de incentivar a cooperação e o diálogo entre os aprendizes, está sempre atento a oferecer o suporte adequado (scaffolding) a garantir que os aprendizes compreendam o material da língua veicular utilizado na aula, muitas vezes recorrendo a diferentes meios, como textos, imagens e vídeos, no intuito de facilitar a compreensão (SERRAGIOTTO, 2002 e 2012). Além de incorporar os princípios das teorias socioculturais e construtivistas, o CLIL também abarca os pressupostos da abordagem comunicativa, ao ponto de ser descrito por Graddol como "a metodologia comunicativa por excelência"4 (2006, p. 86). Com efeito, o CLIL, ao promover a comunicação autêntica e ao envolver ativamente os aprendizes, que aprendem a fazer coisas com a língua, tem êxito onde a abordagem comunicativa falha, ou seja, na autenticidade do material, das trocas comunicativas e do contexto em que elas acontecem (DALTON-PUFFER, 2008; NAHARRO, 2019).

Mesmo que um dos principais objetivos do CLIL seja promover o uso autêntico da L2, é importante ressaltar que essa abordagem acomoda também o uso da L1 dos aprendizes. Segundo David Marsh, implementar o CLIL não significa impor a L2 em detrimento da L1, mas promover o translanguaging, ou seja, o uso sistemático de mais de uma língua (por exemplo, a língua materna e a língua adicional), visando a prevenir a frustração dos alunos quando não conseguem comunicar na LE e promovendo, assim, uma atitude mais positiva em relação à língua-alvo (MARSH, 2009). Outro efeito positivo do translanguaging nas aulas de CLIL é que as línguas utilizadas na sala de aula possuem status igual e, por isso, todas elas são vistas como uma ferramenta útil para o desenvolvimento de habilidades cognitivas (HEMMI e BANEGAS, 2021). Naharro (2019) também aponta que, no nível universitário, o code-switching entre a L1 e a L2 é uma prática aceita nas aulas de CLIL, especialmente em atividades em grupos ou nos materiais de suporte, destacando a adaptabilidade dessa abordagem às necessidades e ao contexto dos alunos. Já em contexto da escola primária e secundária, Lasagabatser (2013), na Colômbia, e Luz (2016), no Brasil, constatam que os docentes CLIL permitem o uso da L1 em suas aulas, já que a consideram como ferramenta necessária como suporte (scaffold) na aprendizagem da L2 e dos conteúdos disciplinares.

Resumindo, os pilares do CLIL consistem nos 4 Cs: Conteúdo, Comunicação, Cognição e Cultura (COYLE et al., 2010). De fato, como vimos, o CLIL prevê o ensino/aprendizagem de conteúdo por meio da língua, e da língua por meio do conteúdo, o que implica a realização de atividades comunicativas autênticas. Vimos também que o CLIL visa a promover o engajamento cognitivo dos alunos por meio da aprendizagem colaborativa e de projetos que envolvem processos cognitivos complexos. Por último, faz parte da proposta dessa abordagem a exploração de conteúdos culturais e o desenvolvimento da competência intercultural dos aprendizes, os

4 "the ultimate communicative methodology" (GRADDOL, 2006, p.86) 
quais refletem sobre a cultura da língua veicular assim como sobre a sua própria.

À luz do que foi exposto, pode-se dizer que o CLIL se apresenta como uma abordagem coerente, com princípios norteadores sólidos, alinhados com as teorias socioculturais, segundo as quais a aprendizagem, a integração e a educação intercultural se desenvolvem nas trocas de ideias com os outros (SERRAGIOTTO, 2012). Pelo fato de ser caracterizado por uma grande flexibilidade e adaptabilidade a diferentes contextos, é inevitável que o CLIL assuma aspectos e metodologias didáticas diferentes de acordo com os objetivos e o cenário específicos de sua implementação. De fato, Marsh (2009) reconhece que pode haver diferentes propósitos para recorrer ao CLIL, que podem incluir até o simples desenvolvimento por parte dos alunos de uma atitude positiva em relação à educação linguística. Diferentes objetivos e contextos exigem diferentes metodologias e, inevitavelmente, levarão a resultados distintos na aprendizagem da língua e dos conteúdos, como veremos a seguir.

\subsection{O CLIL na prática e suas tipologias}

A modalidade CLIL se caracteriza por sua flexibilidade, adaptando-se, por exemplo, aos recursos disponíveis, ao tempo, às idades dos aprendizes e a seu nível escolar. Assim, a variedade das aulas CLIL pode ser realmente imensa, indo desde "duchas linguísticas" ("language showers") de 30 minutos semanais, até verdadeiras imersões com diversas aulas conduzidas na língua veicular (cf. LUZ, 2016). De acordo com o contexto, então, nem sempre a língua e o conteúdo da disciplina possuem exatamente o mesmo status na aula de CLIL (SERRAGIOTTO, 2002; BALBONI, 2015). Balboni considera que há um continuum (Quadro 2), onde podemos ver que o CLIL pode ser implementado dando uma ligeira preferência para o conteúdo ou para a língua.

Quadro 2 - Tipos de CLIL

\begin{tabular}{|l|cc|}
\hline & Lingua straniera & Chimica \\
\hline Non-CLIL & Si fa chimica in inglese \\
& senza alcun interesse \\
& per l'eventuale acquisizione \\
& dell'inglese \\
\hline CLIL orientato & Si fa chimica in inglese \\
sulla chimica & e l'insegnante di inglese \\
& dà un supporto in aspetti \\
& linguistici utili per la chimica \\
\hline
\end{tabular}




\begin{tabular}{|c|c|}
\hline CLIL & $\begin{array}{l}\text { Chimica e inglese perseguono } \\
\text { i loro obiettivi nello stesso tempo, } \\
\text { con le stesse attivitá; il } \\
\text { contenuto chimico prevale } \\
\text { ma con forte attenzione al ruolo } \\
\text { e al tipo della lingua }\end{array}$ \\
\hline $\begin{array}{l}\text { CLIL orientato } \\
\text { sull'inglese }\end{array}$ & $\begin{array}{l}\text { Progetti, spesso interdisciplinari, } \\
\text { in cui i contenuti chimici (e anche } \\
\text { biologici e fisici) danno i contenuti } \\
\text { a moduli eseguiti poi in inglese }\end{array}$ \\
\hline Non-CLIL & $\begin{array}{l}\text { Il tradizionale corso di microlingua } \\
\text { in cui si usano i testi di chimica } \\
\text { ma per imparare l'inglese } \\
\text { della chimica, non la chimica }\end{array}$ \\
\hline
\end{tabular}

Fonte: Balboni (2015, p.215)

Essa distinção proposta por Balboni é parecida com aquela que se faz entre Soft CLIL, ou seja, uma versão do CLIL concentrada no ensino de língua, e o Hard CLIL, em que se dá preferência ao conteúdo (cf. LUZ, 2016). Existe também o Modular CLIL, que prevê o ensino de alguns componentes curriculares de determinada disciplina na língua adicional. Essa versão modular tem sido considerada como uma ponte entre o ensino tradicional e a abordagem CLIL, pois permite uma primeira experimentação desse modelo no contexto específico em que ele poderia depois vir a ser implementado (LUZ, 2016).

É importante considerar, no entanto, que a forma como o CLIL será implementado no nível prático depende não somente da maior orientação para a língua ou para o conteúdo, mas de outros fatores, como a língua veicular escolhida e os recursos sobre os quais se pode contar. É comum que, quando se fala em CLIL, as pessoas logo pensem na língua inglesa, que tem sido ensinada e aprendida com essa abordagem desde os anos 1990. No entanto, o CLIL pode ser usado para promover outras línguas: na Itália, por exemplo, é utilizado para promover o espanhol, o francês e o alemão (NAHARRO, 2019), ao passo que na Austrália é usado para promover as LOTE (Languages Other Than English), ou seja, línguas asiáticas, europeias ou de herança (COYLE et al., 2010).

Quando as línguas já fazem parte do currículo escolar, os alunos têm um primeiro contato com a língua alvo por meio de aulas formais e somente em um segundo momento a abordagem CLIL é introduzida (SERRAGIOTTO, 2002). Contudo, em casos de línguas próximas, é possível prescindir desse ensino formal, pois, até nos níveis iniciais, os aprendizes podem usar as semelhanças entre a L2 e a L1 a seu favor (SERRAGIOTTO, 2012), desenvolvendo a 
intercompreensão, ou seja, a capacidade de se compreenderem variedades de diferentes línguas da mesma família. Baraldi e Santoro (2020) demonstram que alunos brasileiros podem desenvolver estratégias de leitura que os ajudam a compreender textos escritos retirados de jornais e periódicos em diferentes línguas românicas, inclusive o italiano. Supõe-se, portanto, que, especialmente no caso de aprendizes principiantes, a proximidade entre a língua materna e a língua veicular incida de forma positiva no tipo de atividades que podem ser realizadas na abordagem CLIL, especialmente quanto às habilidades receptivas.

O modelo CLIL será adaptado também de acordo com os recursos disponíveis em cada contexto específico, não só em termos de aparelhagem tecnológica, mas também de recursos humanos, ou seja, os professores que possuem as competências para a implementação da abordagem CLIL (PÉREZ CAÑADO, 2017). A primeira delas é, sem dúvida, a competência linguística, o que não significa que o professor precise necessariamente ter níveis avançados de proficiência. De acordo com Marsh (2009), os professores CLIL podem ter uma proficiência limitada na língua alvo, pois eles não são os únicos responsáveis pelas aulas, mas devem poder contar com a ajuda de especialistas do ensino de línguas, como os professores da L2, ou, alternativamente, formadores e consultores externos à escola de atuação. O CLIL, portanto, serve também para promover o diálogo e a colaboração entre professores de língua com professores de outras disciplinas (SERRAGIOTTO, 2002). Ademais, espera-se que os docentes tenham também competência pedagógica, além de possuir conhecimentos científicos não só sobre a disciplina da qual são responsáveis, mas também sobre os pressupostos teóricos e metodológicos do CLIL como, por exemplo, as metodologias centradas no aprendiz (PÉREZ CAÑADO, 2017). É justamente para aprimorar essas competências que um curso de formação é necessário.

\subsection{O CLIL e a formação de professores}

Como sugere Serragiotto (2002), para que os professores deem aulas na modalidade CLIL, é necessário que tenham acesso a cursos tanto de língua quanto de didática. No entanto, mesmo nos países europeus, onde o CLIL vem tendo bastante adesão desde os anos 1990, até recentemente os programas de formação para os professores de CLIL eram ainda escassos (PÉREZ CAÑADO, 2014) e até hoje há poucos estudos e pesquisas sobre como essa formação é conduzida pelos educadores e recebida pelos professores (HE e LIN, 2018).

Por exemplo, espera-se que um docente CLIL tenha "la capacità di scegliere dei materiali autentici e le risorse CLIL in base al contenuto, al livello linguistico e alle esigenze degli allie$v i$ " (SERRAGIOTTO, 2012, p. 58), mas para que um professor consiga operar essas escolhas, é necessário que ele adquira certa sensibilidade linguística, ou Teacher Language Awareness (HE e LIN, 2018). Essa sensibilidade vai além da proficiência linguística, pois trata-se de refletir sobre o papel importante que a língua exerce na aprendizagem (VYGOTSKY, 1978), um papel que é muitas vezes subestimado ou ignorado em uma aula conduzida na língua materna. O docente CLIL se encontra a refletir sobre novas questões e a ver sua própria disciplina por uma nova perspectiva, começando a refletir sobre o material que será selecionado para suas aulas e, principalmente, sobre como os aprendizes poderão interagir com esse material de forma a desenvolver, ao mesmo tempo, seu conhecimento da língua e do conteúdo. Além de desenvolver essa sensibilidade linguísticas, os professores CLIL também desenvolvem uma sensibilidade intercultural, pois ensinar a própria matéria em outra língua oferece a "possibilità di sviluppare opportunità multiculturali e favorire la conoscenza da molteplici punti di vista" (SERRAGIOTTO, 2012, p. 56). O papel do formador, então, consiste em guiar os professores no desenvolvimento dessas novas perspectivas sobre o papel da língua e da cultura nas suas 
disciplinas, o que, de acordo com He e Lin (2018), acontece por meio da colaboração e do diálogo entre professor e formador.

\subsection{CLIL no Brasil}

Com o aumento no número de escolas bilíngues no Brasil, há um crescente interesse na abordagem CLIL, que tem tido grande adesão nos últimos anos. No entanto, os estudos sobre sua implementação nas escolas brasileiras são ainda escassos e se concentram no uso do inglês como língua veicular (LUZ, 2016; LANDAU, ALBUQUERQUE PARANÁ e SIQUEIRA, 2021), havendo poucas incursões em outras línguas, como o alemão (GRILLI, 2019). Apesar de ainda serem escassas, as pesquisas apontam que o CLIL tem grande potencial no Brasil, também no contexto da escola pública, onde essa abordagem parece promover a motivação dos aprendizes tanto na aprendizagem da língua veicular, quanto na aprendizagem dos conteúdos (LUZ, 2016).

Serragiotto (2012) enfatiza as vantagens de se prover o modelo CLIL no Brasil usando o italiano como língua veicular. Em um mundo em que o multilinguismo é cada vez mais exigido (PÉREZ-CAÑADO, 2017), é necessário pensar que a formação dos alunos deve promover o contato "con realtà linguistiche che non si appiattiscono soltanto sulla conoscenza della lingua inglese" (p. 61). Além disso, a proximidade entre italiano e português favorece o uso do italiano como língua veicular, já que não representaria um grande obstáculo para a compreensão de conteúdos (cf. BARALDI e SANTORO, 2020). Serragiotto (2012) também afirma que o italiano não deve ser imposto como única língua de comunicação na aula de CLIL, já que recorrer às práticas de code-switching e translanguaging pode trazer contribuições importantes tanto para a competência metalinguística dos aprendizes, que comparam a L1 à L2, quanto para a conscientização intercultural, pois os conteúdos são vistos por uma nova perspectiva. Por fim, a escolha do italiano como língua veicular se justifica também, do ponto de vista sociocultural, pelas "radici profonde che legano l'Italia al Brasile" (p. 64), e, do ponto de vista econômico, pela estreita colaboração entre as empresas italianas e aquelas da comunidade ítalo-brasileira no Brasil. Havendo todos esses pressupostos que favorecem a promoção da língua italiana nas escolas brasileiras, Serragiotto aponta que a abordagem CLIL necessita de apoio e projetos dos órgãos governamentais competentes, que é justamente o objetivo do programa multicultural em língua italiana promovido pela RMESP e pelo Consulado italiano de São Paulo.

\section{Metodologia: o projeto, os alunos e a coleta de dados}

Os dados apresentados neste trabalho foram coletados em uma turma de professores da RMESP, responsáveis por diferentes disciplinas, que estavam cursando o módulo de didática do Programa de Formação Multicultural em Língua Italiana (PFMLI). Nesta seção, descreveremos o contexto em que esse módulo foi ministrado, a turma de professores que participou do estudo e os métodos de coleta de dados. 


\subsection{O "Suporte didático para o ensino da língua italiana"}

"Suporte didático para o ensino da língua italiana" (doravante SD) foi o nome dado ao módulo de didática do PFMLI, ministrado para os professores da RMESP que já tinham completado um ou dois semestres de língua italiana em cursos organizados pelo ICIB.

De acordo com o edital do projeto, esse módulo tinha como objetivo tanto uma formação linguística, com conteúdos de língua italiana, quanto uma formação didática, com conteúdos relativos à didática das línguas em diferentes contextos: a educação infantil, o ensino fundamental e o ensino médio. O edital também explicitava que um dos objetivos do módulo consistia na elaboração de projetos didáticos para o ensino de italiano que pudessem ser utilizados no contexto de atuação dos docentes.

A elaboração mais detalhada do programa curricular do módulo didático foi conduzida pelo grupo de formadoras, que consistia de sete alunas e ex-alunas do Programa de Pós-Graduação em Língua, Literatura e Cultura Italianas, com a orientação de uma professora de língua italiana da Universidade de São Paulo e do coordenador pedagógico do ICIB.

Decidiu-se que o programa do módulo contemplaria o ensino por projetos (cf. RIDARELLI, 1998), a abordagem CLIL (cf. BIER, 2018), os métodos de ensino de línguas (cf. SERRA BORNETO, 1998), a abordagem lúdica (cf. CAON e RUTSKA, 2010) e a elaboração de unidades didáticas (cf. LUISE, 2002). Percebe-se, então, que o SD não foi pensado como uma formação para professores CLIL, mas como uma formação mais ampla. Apesar de o CLIL não ter sido o principal foco do $\mathrm{SD}$, percebemos que teve um papel muito importante, tanto no planejamento das aulas por parte das formadoras, quanto nos projetos elaborados pelos professores ao longo do semestre.

O SD foi realizado durante 15 semanas, entre os meses de setembro a dezembro de 2020 , com uma carga horária correspondente a 30 horas. Devido à pandemia de Covid-19, foi conduzido on-line, com aulas síncronas semanais realizadas por meio da plataforma Zoom. Neste trabalho, nos concentraremos nas aulas realizadas por uma das formadoras com uma turma de professores do ensino fundamental.

\subsection{Os participantes}

Os dados aqui apresentados foram coletados em uma turma específica do SD, composta por professores de ensino fundamental. Todos eles começaram o SD depois de completar dois semestres de curso de língua junto ao ICIB. A turma, no início do semestre, contava com oito alunos, mas somente cinco concluíram o módulo e, desses, quatro autorizaram o uso de seus dados para este trabalho (Quadro 3). 
Quadro 3 - Professores participantes

\begin{tabular}{|l|l|l|l|}
\hline $\begin{array}{l}\text { Nome do(a) } \\
\text { professor(a) }\end{array}$ & Contexto de atuação & Disciplina ensinada & $\begin{array}{l}\text { Anos de experiência } \\
\text { na RME }\end{array}$ \\
\hline Amanda & Ensino Fundamental II & Matemática & Menos de 10 \\
\hline Giulia & Ensino Fundamental I & Alfabetização & Mais de 10 \\
\hline Junior & $\begin{array}{l}\text { Fundamental I } \\
\text { Fundamental II } \\
\text { Educação de Jovens e } \\
\text { Adultos (EJA) }\end{array}$ & Educação física & Mais de 10 \\
\hline Marina & Ensino Fundamental I & $\begin{array}{l}\text { Língua portuguesa, } \\
\text { matemática, ciências, } \\
\text { história e geografia }\end{array}$ & Mais de 10 \\
\hline
\end{tabular}

Fonte: A autora

Percebe-se que o grupo era relativamente heterogêneo, com professores atuando em diferentes contextos (Fundamental I, Fundamental II e Educação de Jovens e Adultos) e sendo responsáveis por diferentes disciplinas. Todos os professores tinham extensa experiência em sala de aula, que, na maioria dos casos, superava os dez anos.

A formadora, que havia recentemente concluído seu doutorado em ensino de italiano, tinha experiência de 18 anos como professora de língua e também havia trabalhado em cursos de formação de professores. Apesar de não ser especialista em CLIL, já estava familiarizada com essa abordagem.

\subsection{Coleta de dados}

Os dados apresentados na próxima seção foram coletados ao longo do SD com os professores da turma descrita acima. São compostos por respostas a atividades escritas, questionários online realizados no início e no final do SD e projetos elaborados por cada professor. Foi analisado também o diário que a formadora manteve durante o $\mathrm{SD}$, anotando as atividades realizadas em cada aula, assim como observações sobre a participação dos professores.

\section{Os papéis do CLIL no Suporte Didático}

Como já foi dito na introdução, no contexto analisado, o modelo CLIL teve duas funções, já que foi tanto a abordagem adotada pela formadora quanto um dos conteúdos estudados no SD, influenciando, de forma mais ou menos direta, a elaboração dos projetos finais.

5 Para salvaguardar a identidade dos professores, optamos por usar pseudônimos. 


\subsection{O CLIL como abordagem adotada no Suporte Didático}

A formadora responsável pelas aulas do SD na turma em análise não partiu de um programa curricular previamente pensado na abordagem CLIL, no entanto, pelo fato de os conteúdos didáticos terem sido abordados em língua italiana e pelo fato de ter sido dada uma atenção específica também ao desenvolvimento linguístico dos professores, pode-se considerar que o SD foi conduzido em modalidade CLIL para todos os efeitos.

Em qualidade de professora CLIL, então, a formadora sempre teve cuidado de selecionar os textos escritos e orais utilizados nas aulas de acordo com o nível dos aprendizes e oferecendo o suporte necessário para sua compreensão (SERRAGIOTTO, 2014). Nesse sentido, os conteúdos do SD foram apresentados recorrendo a diferentes meios, como textos, imagens e vídeos. Por exemplo, a introdução ao método dos projetos aconteceu tanto por meio da leitura de um texto teórico (Figura 1) quanto por meio da visualização de um vídeo (Figura 2), ambos seguidos de perguntas que guiavam a compreensão de conceitos-chave. Como ressalta Serragiotto (2002), apresentar o mesmo conteúdo fazendo uso de diferentes materiais cuidadosamente selecionados e didatizados para oferecer o suporte (scaffolding) necessário aos alunos é extremamente importante na abordagem CLIL. 
Figura 1 - Atividade realizada por meio da leitura de textos

Per la prossima lezione, leggi il testo qui sotto e rispondi alle domande che seguono:

\section{IL METODO DEI PROGETTI}

\section{Mario Fierli}

\section{Aspetti pedagogici generali del metodo dei progetti}

Il metodo dei progetti ha una lunga trattazione nella storia della pedagogia ed alcune precise caratterizzazioni. L'idea che un modo migliore per apprendere sia quello di trovarsi di fronte a compiti "reali" piuttosto che a percorsi didattici nei quali gli apprendimenti sono opportunamente frazionati e messi in frequenza è, probabilmente, molto antica. Ma l'atto di nascita ufficiale è dato dal libro "Project Method "con cui nel 1918 il pedagogista Kilpatrick lo sosteneva e teorizzava. La proposta si inquadra nella filosofia pragmatista americana ed è strettamente collegata alla pedagogia di Dewey. Ne sono segni evidenti l'importanza data a un apprendimento:

- Attivo;

- legato alla soluzione di problemi dotati di senso sia dal punto di vista cognitivo sia dal punto di vista del contesto sociale in cui si collocano;

- capace di sviluppare contemporaneamente abilità intellettuali e aspetti della personalità come il senso di responsabilità e di autodeterminazione;

Il metodo dei progetti è rimasto poi al centro di tutte le correnti pedagogiche attivistiche che ne hanno messo in luce di volta in volta valenze diverse.

Anzitutto, la proposta di Kilpatrick non è diretta ad un particolare livello scolastico, ma vale in generale. Il metodo non si riferisce solo a particolari assi culturali, ma si estende a tutte le discipline, a volte integrandole fra loro. Inoltre, anche se si parla di "metodo", in realtà esso può comprendere molti tipi di attività con profili cognitivi diversi. 
Figura 2 - Atividade realizada por meio da visualização de vídeos

Per la prossima lezione, guarda il video "Kilpatrick e il metodo dei progetti" e rispondi alle domande:

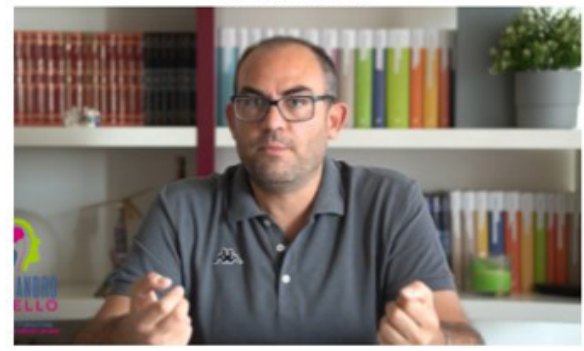

1. Secondo Kilpatrick, qual è il ruolo della scuola nella formazione?

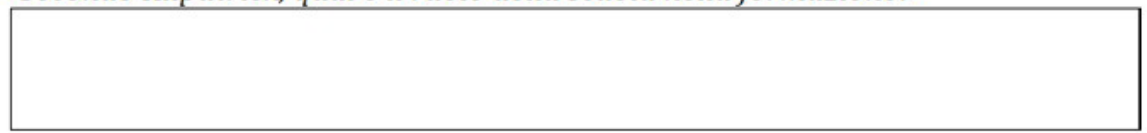

2. Qual è la funzione dell' "agire" e dei "problemi" nel metodo di Kilpatrick?

Apesar de não ser uma característica própria somente do CLIL, a prática do translanguaging também foi muito presente nas aulas do SD. Nos encontros síncronos, pedia-se frequentemente para que os professores trabalhassem em grupo, de forma a estimular a troca de ideias e a aprendizagem colaborativa não só dos conteúdos, mas também da língua, seguindo os princípios socioculturais que orientam a metodologia CLIL (SERRAGIOTTO, 2012; NAHARRO, 2019; HEMMI e BANEGAS, 2021). Os grupos eram livres para conduzirem as discussões na L1, mas o resultado da discussão deveria ser antes escrito e depois relatado em língua italiana. A possibilidade de utilizar a L1 nas discussões em grupos ajudou a reduzir os níveis de ansiedade relacionados com a comunicação na L2, prevenindo frustrações, promovendo uma atitude positiva em relação ao italiano (MARSH, 2009) e servindo como um importante suporte na aprendizagem da L2 (LASAGABASTER, 2013; LUZ, 2016; NAHARRO, 2019). Além disso, a produção colaborativa de um texto em italiano visava a desenvolver a habilidade linguística e, ao mesmo tempo, servia como instrumento de scaffolding para facilitar a produção oral na L2 que aconteceria em seguida (SERRAGIOTTO, 2014). De fato, os professores perceberam a diferença de abordagem em relação às aulas de L2 que tinham tido nos módulos anteriores, como mostra o depoimento da professora Amanda no questionário de avaliação final: 
$\mathrm{O}$ curso, da forma em que foi realizado, surpreendeu as minhas expectativas, principalmente porque passamos de estudantes passivos para ativos, assim, pudemos praticar a conversação (Amanda)

O papel mais ativo dos estudantes, mencionado pela professora, corresponde a um dos princípios norteadores da abordagem CLIL, como afirmam Coyle et al. (2010) em seu livro.

Outra característica fundamental do modelo CLIL, como vimos, é a integração de conteúdo e língua, algo que a formadora sempre levou em consideração em suas aulas. Foi, por exemplo, o que aconteceu no momento de abordar o método dos projetos. Para isso, os professores leram textos em que eram descritas as fases de implementação de diversos projetos mirados ao ensino de L2 (RIDARELLI, 1998). Após a leitura, os aprendizes realizaram uma atividade em que precisavam completar os passos de um dos projetos conjugando os verbos no passato prossimo, o assunto linguístico que estava sendo revisado. No mesmo exercício, os professores também precisavam demonstrar que sabiam associar os diferentes passos do projeto às fases que haviam sido introduzidas nos textos escritos (parte da atividade pode ser vista na Figura 3). Finalmente, a atividade previa que os professores descrevessem projetos que eles mesmos tinham realizado em suas carreiras, fazendo, portanto, mais uma vez uso do passato prossimo. Essa atividade é um exemplo bem-sucedido de integração entre a língua veicular e os conteúdos abordados (COYLE et al. 2010; SERRAGIOTTO, 2012), já que para falar de projetos realizados é essencial usar o passado. 
Figura 3 - A integração de língua e conteúdo: o passato prossimo para relatar os passos e as fases dos projetos didáticos

\begin{tabular}{|l||}
\hline \multicolumn{3}{|c|}{ Supporto didattico per l'insegnamento della lingua italiana } \\
Attività 4a - Passato prossimo e progetti \\
\hline \multirow{2}{*}{ a) Il resoconto di un progetto: completiamo con i verbi al passato prossimo } \\
\hline b) Poi identifichiamo le diverse fasi del progetto
\end{tabular}

A integração de língua e conteúdo, no entanto, não foi sempre tão eficaz. De fato, as necessidades e dúvidas linguísticas dos aprendizes, em alguns casos, não eram facilmente integráveis ao conteúdo de didática. Um exemplo disso foram as dúvidas acerca das preposições articuladas, que foram tratadas por meio de exercícios de conscientização linguística (Figura 4) no momento de introduzir a metodologia lúdica. Nesse caso, não se pode falar de verdadeira integração de língua e conteúdo, pois esse exercício não está necessariamente relacionado com o conteúdo abordado naquele momento. Isso demonstra que um professor CLIL precisa desenvolver sua sensibilidade linguística, ou Teaching Language Awareness, por meio da reflexão sobre sua própria prática (HE e LIN, 2018). Essa sensibilidade linguística, particularmente apurada em professores de línguas, assume novas facetas no contexto CLIL, em que não é suficiente ser sensível a aspectos linguísticos, mas é também necessário perceber as maneiras como 
a língua e o conteúdo interagem entre si. De acordo com a perspectiva sociocultural de $\mathrm{He}$ e Lin, essa sensibilidade se desenvolve particularmente quando o professor tem a oportunidade de dialogar com um par mais competente (VYGOTSKY, 1978). Isso, como veremos, é o que aconteceu na interação entre os professores e a formadora.

Figura 4 - A integração de língua e conteúdo: um exemplo de integração parcial

\section{La metodologia ludica}

Cosa si intende esattamente quando si parla di didattica ludica?

La metodologia ludica è una pratica didattica che prevede l'uso di tecniche basate sulla ludicità e sul gioco. È bene anzitutto distinguere questi due concetti: il primo indica un principio in base al quale per promuovere lo sviluppo globale dell' (...) allievo si crea un ambiente di apprendimento rilassante, motivante e allo stesso tempo piacevole. Un contesto ricco di stimoli positivi dove lo studente è protagonista del (...) proprio processo formativo e in cui partecipa ad attività di cooperazione e di competizione positiva con i compagni. Il gioco invece, è una tecnica didattica che, appoggiandosi sulla motivazione intrinseca, permette il conseguimento degli (...) obiettivi e delle (...) mete educative che caratterizzano l'educazione linguistica.

Cosa sono le parole in rosso? Perché sono diverse tra loro? Sapresti trovare altre preposizioni nel testo?

A eficácia da integração entre conteúdo e língua pode ser avaliada medindo a aprendizagem dos alunos nessas duas frentes. Apesar de no SD não terem sido realizados pré-testes e póstestes linguísticos ou de conteúdo que pudessem mostrar claramente o desenvolvimento dos professores, houve um acompanhamento constante da evolução de sua sensibilidade linguística por meio da participação às aulas e da elaboração de um projeto final, que veremos com mais detalhe na próxima seção.

\subsection{A recepção do CLIL pelos professores}

Quando o SD começou, os professores já tinham tido dois semestres de contato com a língua italiana, no entanto, ainda se sentiam inseguros diante da responsabilidade de ensiná-la a seus respectivos alunos. Essa insegurança, que podemos ver representada na resposta de Marina ao questionário coletado no início do curso, era principalmente devida ao fato de os 
professores não serem ainda falantes proficientes da L2 ("Sinto-me insegura, pois não tenho fluência em italiano").

Quando foi introduzida a abordagem CLIL, com a qual os professores não estavam previamente familiarizados, começaram a ser vislumbradas maneiras de aliar o ensino da língua italiana ao ensino das diferentes disciplinas. Pelo fato de os professores se sentirem mais seguros acerca dos conteúdos a serem ensinados, a hesitação derivada da falta de proficiência passou em segundo plano, já que, nas aulas CLIL, não é essencial que o professor tenha um domínio avançado da língua veicular (MARSH, 2009). Tratar a abordagem CLIL no SD revelou-se de extrema importância, como demonstra a grande influência que teve nos projetos finais dos professores.

Em alguns casos, como no projeto do professor Júnior, intitulado "Calcio e italiano", a influência do CLIL não foi explicitada, mas encontra-se presente nas entrelinhas. Em seu trabalho, o professor teve como objetivo dedicar um tópico específico da disciplina de educação física, a saber, o futebol, ao ensino da língua e cultura italianas:

Ho pensato di realizzare un progetto a scuola, dove attraverso il calcio posso insegnare elementi della lingua e della cultura italiana. (Junior)

Nesse caso, mesmo que o professor não tenha mencionado a abordagem CLIL explicitamente em seu projeto, percebe-se que há, de fato, uma forte integração entre língua e conteúdo. Essa integração fica ainda mais evidente quando, nas descrições das unidades didáticas, o professor se propõe a ensinar não só o vocabulário relativo ao futebol (o campo, os elementos, a posição dos jogadores), como também o vocabulário das cores através das camisetas dos times italianos (COYLE et al. 2010). Outro aspecto que insere esse projeto na modalidade CLIL é a abordagem da disciplina por uma nova perspectiva cultural, apontando as semelhanças e diferenças entre Itália e Brasil nas posições dos jogadores, aprendendo sobre os jogadores brasileiros nos times italianos e introduzindo elementos da geografia italiana com base nas cidades de origem dos principais times (Figura 5). Por fim, além de adquirirem aspectos linguísticos e culturais, percebemos que esse projeto atenta para outros aspectos importantes das teorias socioculturais em que se baseia o CLIL, como a promoção da autonomia e da autoestima dos aprendizes (cf. MARSH, 2009; SERRAGIOTTO, 2012; NAHARRO, 2019; HEMMI e BANEGAS, 2021). 
Figura 5 - Projeto "Calcio e italiano"

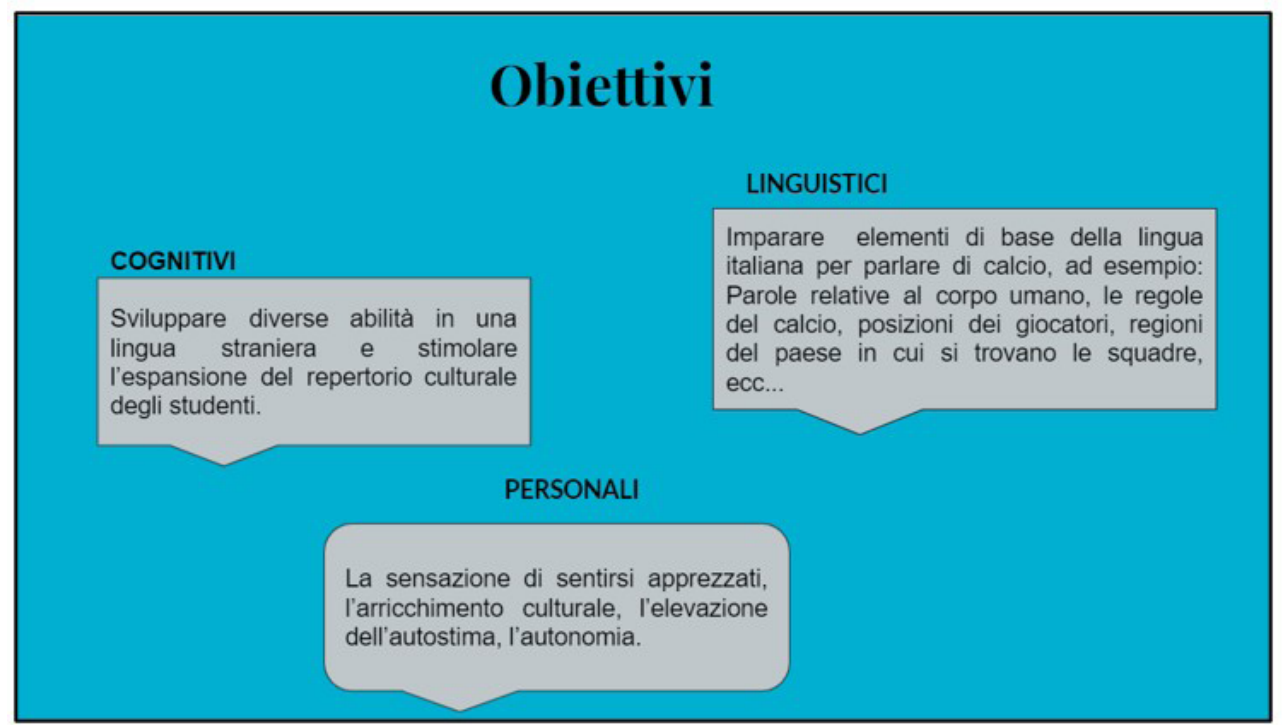

Fonte: Professor de Educação Física

Outro aporte à competência intercultural é dado pelo projeto da professora Giulia, intitulado "Mangiare sano". Nesse caso, o foco é na comida saudável e o objetivo final é a elaboração, em italiano, de um cardápio semanal balanceado. Trata-se de um projeto CLIL e a professora explicita o valor veicular da língua italiana, quando diz: "la lingua italiana sarebbe per loro [gli studenti] uno strumento per appropriarsi dei concetti di scienza” (Giulia).

Além de se tratar de um projeto de grande relevância social, estudar a alimentação pela perspectiva italiana é também uma oportunidade para sensibilizar os alunos às diferenças interculturais, como diz Serragiotto (2012), especialmente se considerarmos a importância da culinária na cultura alvo.

$\mathrm{Na}$ elaboração de todos os projetos, notou-se que, nas interações e trocas com a formadora e com os colegas, os professores foram afinando sua sensibilidade linguística (HE e LIN, 2018; SERRAGIOTTO, 2012). Esse processo se torna particularmente evidente nos projetos das professoras Marina e Amanda.

Em uma atividade em que os professores tiveram que pensar na aplicação da abordagem CLIL a seu contexto de ensino, Marina refletiu sobre como superar a barreira linguística:

Potrei insegnare arte, giochi e canzoni ai bambini. Proverei a superare la barriera linguistica con i giochi, le narrazioni delle storie, spettacoli teatrali realizzati dai bambini, la ripetizione, la esplorazione di altri spazi dentro la scuola, la caccia al 
tesoro, l'insegnamento all'interno di un contesto e promuovendo la comunicazione tra studenti in gruppo. (Marina)

A professora demonstrou criatividade ao enumerar diversas possibilidades de aplicação da abordagem CLIL, mas nesse momento tratava-se ainda de ideias pouco concretas. Seu projeto final, "Astronomia: un divertente viaggio nello spazio", prevê o ensino de conceitos de astronomia em língua italiana por meio de diversas atividades que serão coletadas em um portfólio. Na elaboração do projeto, a professora pesquisou o vocabulário a ser trabalhado com os alunos, desde as características do planeta Terra até as fases lunares e o nome de diversos corpos celestes. Saber qual vocabulário deverá ser efetivamente ensinado ajudou a professora a dar um sentido mais concreto às estratégias que tinha mencionado inicialmente (a saber, o uso de jogos, de histórias, de espaços dentro da escola). Além disso, a integração entre o conteúdo e a língua fica particularmente evidente nas últimas atividades do projeto, quando os alunos terão a oportunidade de associar os planetas aos nomes dos dias da semana em italiano (Figura 6).

Figura 6 - Projeto "Astronomia: un divertente viaggio nello spazio"

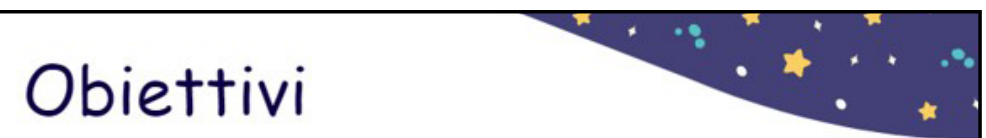

In questo progetto, ci si aspetta che ogni studente possa:

- Imparare alcuni concetti di astronomia in italiano:

- Conoscere una lingua aggiuntiva, oltre all'inglese;

- Interagire con persone in contesti diversi;

- Comprendere le differenze tra il cielo diurno e notturno;

- Conoscere i pianeti del Sistema Solare:

- Imparare le caratteristiche del pianeta Terra;

- Nominare le fasi lunari;

- Mettere in relazione i giorni della settimana con i nomi dei corpi celesti;

- Imparare i nomi dei corpi celesti in italiano: luna, sole, pianeti, stelle, comete, meteore, galassie, ecc;

Fonte: Professora polivalente

A professora Amanda também passou por um processo de afinação da sensibilidade linguística e da capacidade de integrar língua e conteúdo. Por ser professora de matemática, sua primeira reação ao CLIL foi apontar que: "Qualsiasi contenuto di matematica può essere insegnato in italiano, perché la matematica è un linguaggio universale." (Amanda) 
Por isso, sua primeira ideia para o projeto era dar uma aula por semana em italiano com o objetivo final de "insegnare la lingua italiana". No entanto, percebendo que isso implicaria ensinar diferentes conteúdos em italiano, o que seria pouco praticável em seu contexto específico, a professora decidiu repensar sua ideia inicial, chegando à conclusão de que a História da matemática seria um conteúdo específico que poderia ser mais bem integrado ao ensino da língua italiana. Assim, seu objetivo inicial sofreu mudanças consideráveis durante o curso e seu projeto final, "Matematicaliano", consistiu na criação de um livro que apresenta a história da matemática e dos principais matemáticos italianos. $\mathrm{O}$ desenvolvimento da sensibilidade linguística dessa professora fica claro quando olharmos para a descrição das unidades didáticas (Figura 7). Na primeira unidade, por exemplo, um dos objetivos é saber dizer as datas, considerando o dia, o mês, o ano e o século, o que demonstra reflexão acerca da língua necessária para falar sobre personagens da antiguidade. $\mathrm{Na}$ segunda unidade, os alunos aprendem a se apresentar, o que implica um tipo de vocabulário e de estruturas linguísticas necessários à apresentação dos matemáticos no livro que será produzido. Na terceira unidade, em que se aprende a pesquisar a vida dos matemáticos usando palavras-chave em italiano, a professora demonstra levar em consideração não só aspectos linguísticos, mas também os princípios do CLIL, como a pesquisa e a solução de problemas (COYLE et al., 2010; PÉREZ-CAÑADO, 2017).

Figura 7 - Projeto "Matematicaliano"

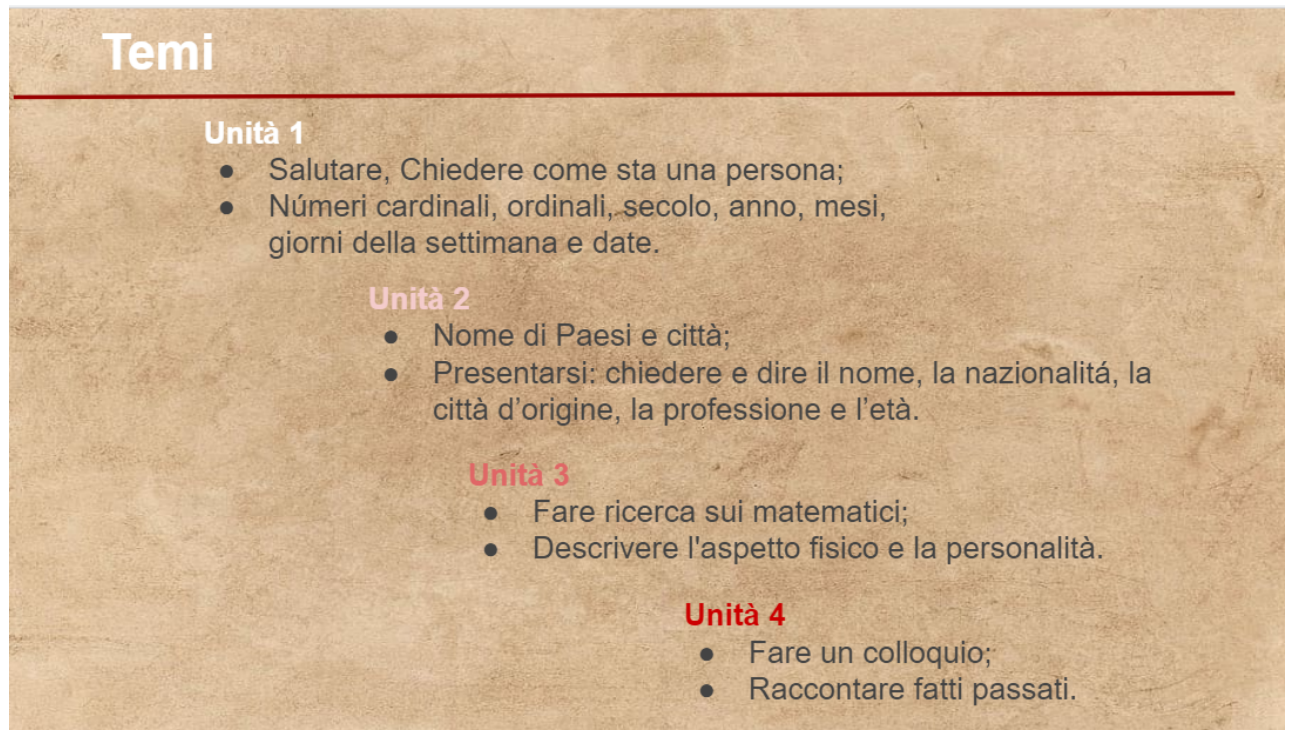

Fonte: Professora de Matemática 
Os objetivos do projeto também mudaram sensivelmente durante a elaboração, tornando-se mais concretos e realistas, como ela aponta neste trecho de seu trabalho:

Espera-se que com este projeto os estudantes aprendam os conceitos básicos de uma segunda língua e percebam que não é impossível a sua compreensão para se comunicar, entender um texto na sua totalidade, falar de si mesmo e contar a respeito de alguém ou de algum lugar. (Amanda)

Nesses objetivos estabelecidos pela professora Amanda, se reafirma a flexibilidade do CLIL. Como vimos, não se trata de uma abordagem rígida que visa exclusivamente a fazer com que os aprendizes atinjam altos níveis de proficiência, mas de uma abordagem que consegue acomodar diferentes propósitos, inclusive o simples objetivo de desenvolver uma atitude positiva em relação à aprendizagem de idiomas (MARSH, 2009). Além disso, nesse trecho, observa-se que a professora percebe como a semelhança entre italiano e português pode ser usada em seu favor, contando com a intercompreensão (cf. SERRAGIOTTO, 2012; BARALDI e SANTORO, 2020).

Nota-se, então, que, ao longo do SD, os professores, enquanto desenvolviam seus projetos, aprimoravam também sua sensibilidade linguística, aprendendo a enxergar a língua e o conteúdo das disciplinas ensinadas na perspectiva de um docente CLIL, ou seja, tentando encontrar pontos de integração entre conteúdos e língua e percebendo as vantagens de trabalhar com línguas que apresentam diferentes pontos de contato.

\section{Considerações finais}

Neste trabalho, começamos tentando definir o CLIL, uma abordagem inovadora que integra o ensino e aprendizagem de língua e conteúdo. Apesar de seu estudo no Brasil estar frequentemente associado à língua inglesa, vimos que essa abordagem também tem potencialidade tanto nos cursos de formação de professores, quanto em projetos modulares para o ensino de italiano e de outras línguas.

Os dados aqui apresentados foram coletados junto a uma turma de professores que participaram do suporte didático (SD) do PLMI promovido pela RMESP em convênio com o consulado italiano, com o ICIB e com o Programa de Pós-Graduação em Língua, Literatura e Cultura Italianas da Universidade de São Paulo. Em primeiro lugar, nos concentramos na forma como as aulas do SD foram elaboradas e conduzidas, analisando os recursos fundamentais da modalidade CLIL utilizados pela formadora. Observou-se que as aulas foram pensadas planejando diversas oportunidades para a realização de atividades colaborativas (COYLE et al., 2010; SERRAGIOTTO, 2012) e conferindo aos professores o papel de aprendizes ativos, como eles mesmos reconheceram. Nas atividades em grupos, os professores eram livres para escolher a língua da interação, o que promoveu a prática do translanguaging e do code-switching, em que os aprendizes passavam da L1 à L2 na realização das atividades. Essas práticas oferecem um 
suporte importante na hora de aprender os conteúdos disciplinares e, ao mesmo tempo, promove uma atitude mais positiva em relação à língua-alvo, cujo uso não é imposto aos aprendizes (MARSH, 2009). Por fim, a formadora também atentou para a integração de língua e conteúdo, que, de acordo com o CLIL, precisam ser desenvolvidos juntos. Essa integração não aconteceu sempre de forma eficaz, o que nos leva a considerar a hipótese de que o tipo de sensibilidade linguística (ou teacher language awareness) necessária para um docente CLIL exige particular atenção à relação entre a língua e o conteúdo que será ensinado naquela língua (HE e LIN, 2018), portanto, não corresponde exatamente à sensibilidade linguística de um professor de L2/LE.

A abordagem CLIL também constituiu um dos conteúdos de didática abordados durante o $\mathrm{SD}$, influenciando os trabalhos finais dos professores. Praticamente todos os projetos realizados pelos docentes da turma em análise se propuseram a implementar a abordagem CLIL em seu formato modular (LUZ, 2016), ou seja, um projeto em que um conteúdo (ou módulo) de uma disciplina seria ensinado em italiano. A percepção de que podiam ensinar um conteúdo familiar por meio do italiano como língua veicular ajudou a diminuir os níveis de ansiedade entre os professores, que, no início, se sentiam inseguros em relação à sua competência linguística. A flexibilidade e adaptabilidade da abordagem CLIL certamente foi fundamental nesse processo, pois os professores, em seus projetos, puderam estabelecer os objetivos que consideravam mais adequados a seu contexto específico (PÉREZ-CAÑADO, 2017). Durante o SD, no entanto, ficou evidente que ensinar em formato CLIL, se por um lado não é a mesma coisa que ensinar uma L2/LE, tampouco é igual a ensinar determinado conteúdo curricular "em outra língua", como acontece no content-based teaching. $\mathrm{O}$ formato CLIL exige certa integração entre língua e conteúdo, de forma que os aprendizes possam "aprender enquanto usam" a língua veicular (COYLE et al., 2010), ao mesmo tempo em que aprendem os conteúdos curriculares. Ser docente CLIL, então, significa desenvolver certa sensibilidade linguística e perceber o importante papel da língua (ou, melhor, das línguas) no processo de aprendizagem (VYGOTSKY, 1978). $\mathrm{Na}$ aula CLIL essas questões tomam relevância maior em relação ao que acontece nas aulas conduzidas na L1 e, por isso, os professores de conteúdos precisam desenvolver essa sensibilidade para poder preparar aulas que, de fato, integrem a língua e os conteúdos. Assim, para preparar projetos CLIL, mesmo que em formatos modulares, é necessário que os professores de conteúdo possam ter acesso a especialistas do ensino de idiomas, como aconteceu no curso de formação aqui descrito (cf. SERRAGIOTTO, 2012). Nas trocas dos professores com os colegas e com a formadora, eles puderam desenvolver um projeto que integrasse efetivamente a língua aos conteúdos, com resultados positivos. No entanto, como bem colocou a professora Amanda em sua avaliação final,

Como em todos os ensinos de línguas, não podemos parar; para realizarmos nossos projetos, é fundamental que tenhamos suporte para colocá-los em andamento na Unidade Escolar. (Amanda) 
Com efeito, não se pode exigir que o professor de determinada disciplina esteja automaticamente pronto para ensinar na modalidade CLIL e, por isso, é necessário que possa sempre contar com um suporte adequado, seja por meio de colaboração com professores da língua veicular, seja por meio da orientação de um especialista em ensino de línguas (COYLE et al., 2010; PÉREZ CAÑADOS, 2017).

Como vimos, os projetos modulares podem ter uma função ponte (LUZ, 2016), ou seja, podem ser o primeiro passo no processo de introdução da abordagem CLIL nas escolas. Os projetos desenvolvidos pelos professores do SD podem ser essa ponte para que o CLIL em língua italiana entre na RMESP. Essa abordagem, de fato, pode ser uma solução viável para introduzir o italiano e outras línguas românicas na escola pública brasileira, aumentando o acesso dos alunos às línguas estrangeiras (CARAMORI, 2018) e promovendo assim o plurilinguismo, ou, pelo menos, a sensibilização dos alunos acerca de outras línguas estrangeiras não hegemônicas (SERRAGIOTTO, 2012; PÉREZ CANÃDOS, 2017). Para que isso aconteça, no entanto, como afirma Serragiotto (2012), é necessário que os órgãos responsáveis do poder público tornem isso possível.

\section{Referências}

BANEGAS, D. L.; HEMMI, C. CLIL: Present and Future. In: C. HEMMI; D. L. BANEGAS (orgs.); International Perspectives on CLIL. Cham: Springer International Publishing, 2021, p.281-295. Disponível em: <https://link.springer.com/10.1007/978-3-030-70095-9_14>. Acesso em: 8/7/2021.

BARALDI, L. D.; SANTORO, E. Ensinar intercompreensão em línguas românicas: uma pesquisa exploratória com aprendizes de italiano. Revista de Italianística, v. 40, 2020, p. 67-93. DOI: https://doi. org/10.11606/issn.2238-8281.i40p67-93

BIER, A. La motivazione nell'insegnamento in CLIL. Venezia: Edizioni Ca' Foscari, 2018.

CAON, F.; RUTSKA, S. La glottodidattica ludica. Venezia: Laboratorio Itals, Ca' Foscari, 2010.

CAPRARA, L. D. S.; MORDENTE, O. A. Panorama dell'italiano in San Paolo nel contesto plurilinguistico brasiliano. Revista de Italianística, v. 9, 2004, p. 101-112. DOI: https://doi.org/10.11606/ issn.2238-8281.v0i9p101-112 .

CARAMORI, A. P. Prefácio. O italiano na esfera pública brasileira: Relatos, percursos e experiências de ensino e aprendizagem. Belo Horizonte: CEFET-MG, 2019, p. 10-12.

COMISSÃO EUROPEIA. Content and Language Integrated Learning (CLIL) at school in Europe. Brüssel: Eurydice, 2006.

COONAN, C. M. Opportunità di usare la LS nella lezione di CLIL: importanza, problemi, soluzioni. Studi di Glottodidattica, 2009, p. 20-34.

COYLE, D.; HOOD, P.; MARSH, D. CLIL: content and language integrated learning. Cambridge, UK; New York: Cambridge University Press, 2010.

DALTON-PUFFER, C. Outcomes and processes in Content and Language Integrated Learning (CLIL): current research from Europe. In: DELANOY, W.; VOLKMANN, L. (orgs.); Future Perspectives for English Language Teaching. Heidelberg: Carl Winter, 2008, p.139-157.

DALTON-PUFFER, C.; NIKULA, T.; SMIT, U. Language use and language learning in CLIL: Current findings and contentious issues. In: DALTON-PUFFER, C.; NIKULA, T.; SMIT, U. (orgs.). AILA 
Applied Linguistics Series, v.7. Amsterdam: John Benjamins Publishing Company, 2010, p.279-292. Disponível em: <https://benjamins.com/catalog/aals.7.14dal>. Acesso em: 8/7/2021.

GRADDOL, D. English Next: Why global English may mean the end of "English as a Foreign Language”. UK: British Council, 2006.

GRILLI, Marina. CLIL em alemão no Brasil e a competência de leitura dos graduandos em Letras/ Alemão. Pandaemonium Germanicum, v. 22, n. 38, 2019, p. 48-74. DOI: https://doi.org/10.11606/19828837223848.

HE, P.; LIN, A. M. Y. Becoming a "language-aware" content teacher: Content and language integrated learning (CLIL) teacher professional development as a collaborative, dynamic, and dialogic process. Journal of Immersion and Content-Based Language Education, v. 6, n. 2, 2018, p. 162-188. DOI: https:// doi.org/10.1075/jicb.17009.he .

LANDAU, Julia; ALBUQUERQUE PARANÁ, Raul; SIQUEIRA, Sávio. Sistemas Educacionais (SE) and CLIL Developments in Brazil: From Promises to Prospects. In: HEMMI, C.; BANEGAS, D. L. (org.). International Perspectives on CLIL. International Perspectives on English Language Teaching. Cham: Springer International Publishing, 2021, p. 259-279. DOI: https://doi.org/10.1007/978-3-03070095-9 13.

LASAGABASTER, D. The use of the L1 in CLIL classes: The teachers' perspective. Latin American Journal of Content and Language Integrated Learning, v. 6, n. 2, 2013, p. 1-21. DOI: https://doi. org/10.5294/lacli1.2013.6.2.1.

LUISE, M. C. Insegnare l'italiano all'estero: cenni per una glottodidattica a misura di bambino. In: DOLCI, R.; CELENTIN, P. (Orgs.); La formazione di base del docente di italiano per stranieri. 2a ed. Roma: Bonacci, 2002, p.103-116.

LUZ, D. S. Inglês na escola pública: uma proposta pedagógica baseada na metodologia CLIL, 2016. Dissertação (Mestrado em Letras) - Universidade Estadual do Sudoeste da Bahia, Vitória da Conquista, 145 f., 2016. Disponível em: <http://www2.uesb.br/ppg/ppgcel/wp-content/uploads/2017/07/Disserta\%C3\%A7\%C3\%A3o-Mestrado-em-Letras-UESB-Turma-2014-Dimas-Silva-Luz.pdf $>$. Acesso em: 6/6/2021

MARSH, D. CLIL: An interview with Professor David Marsh. 2009. Disponível em: <http://ihjournal.com/content-and-language-integrated-learning >. Acesso em: 10/4/2021.

NAHARRO, M. J. Moving Towards a Revolutionary Change in Multilingual Education: does CLIL live up to the Hype? Journal of e-Learning and Knowledge Society, v. 15, n. 1, 2019, p. 109-120. DOI: https://doi.org/10.20368/1971-8829/1575.

ORTALE, F.; ZORZAN, F. J. DE A. Mapeamento dos municípios com ensino de italiano em escolas públicas. Revista de Italianística, v. 2, n. 26, 2013, p. 121. DOI: https://doi.org/10.11606/issn.2238-8281. v2i26p121-144.

PÉREZ CAÑADO, M. L. Teacher training needs for bilingual education: in-service teacher perceptions. International Journal of Bilingual Education and Bilingualism, v. 19, n. 3, 2016, p. 266-295. DOI: https://doi.org/10.1080/13670050.2014.980778.

PÉREZ CAÑADO, M. L. CLIL Teacher Education: Where do we Stand and Where do we Need to Go? In: PARRA, M. E. G.; JOHNSTONE, R. (orgs.) Educación bilingüe: tendencias educativas y conceptos clave. Gobierno de España: Ministerio de Educación, Cultura y Deporte, 2017, p.129-144. DOI: https://doi.org/10.4438/030-17-133-4

PEREZ CAÑADO, M. L.; RAEZ PADILLA, J. Introduction and Overview. In: MARSH, D.; PEREZ 
CANADO, M. L.; RAEZ PADILLA, J. (orgs.). CLIL in action: voices from the classroom. Newcastle upon Tyne, UK: Cambridge Scholars Publishing, 2015, p.1-14.

RIDARELLI, G. Project work. In: SERRA BORNETO, C. (org.). C'era una volta il metodo: tendenze attuali nella didattica delle lingue straniere. Roma: Carocci, 1998, p.173-187.

RINGBOM, H. On the Distinction between Second-Language Acquisition and Foreign-Language Learning. Papers in Language Learning and Language Acquisition. Papers presented at the Nordic Conference on Applied Linguistics (2nd, Hanasaari), Espoo, Hanasaari, Finlândia, p.37-44, 1979. Disponível em: $<$ https://files.eric.ed.gov/fulltext/ED269973.pdf $>$. Acesso em: 18/2/2021.

SERRA BORNETO, C. (Org.). C'era una volta il metodo. Roma: Carocci, 1998.

SERRAGIOTTO, Graziano. L'italiano come lingua veicolare: insegnare una disciplina attraverso l'italiano. In: DOLCI, R.; CELENTIN, P. (orgs.). La formazione di base del docente di italiano per stranieri. 2a. ed. Roma: Bonacci, 2002. p. 241-253.

SERRAGIOTTO, G. L'Apprendimento integrato della lingua italiana e di contenuti non linguistici (CLIL) in Brasile. Revista de Italianistica, v. 24, 2014, p. 42-68. DOI: https://doi.org/10.11606/issn.22388281.v0i24p42-68.

VYGOTSKY, L. S. Mind in society: The development of higher mental processes. Cambridge, MA: Harvard University Press, 1978.

Recebido em: 12/07/2021 (versão atualizada: 06/09/2021)

Aprovado em: 03/11/2021

Agradecimentos - Deixo meu agradecimento à colega formadora Luciana Duarte Baraldi, que contribuiu com várias sugestões a este artigo. Agradeço também aos professores que participaram do Suporte Didático, sem os quais essa experiência não teria sido possível, assim como as instituições envolvidas no "Programa de Formação Multicultural em Língua Italiana". 